\title{
BIM Methodology Applied in Structural Design: Analysis of Interoperability in ArchiCAD/ETABS Process
}

\author{
Alcínia Zita Sampaio* (D), Augusto M. Gomes ${ }^{\circledR}$, Tomas Farinha \\ Department of Civil Engineering, University of Lisbon, Lisbon, Portugal \\ Email: ${ }^{\star}$ zita.sampaio@tecnico.ulisboa.pt, augusto.gomes@tecnico.ulisboa.pt, tomas.farinha@tecnico.ulisboa.pt
}

How to cite this paper: Sampaio, A.Z., Gomes, A.M. and Farinha, T. (2021) BIM Methodology Applied in Structural Design: Analysis of Interoperability in ArchiCAD/ ETABS Process. Journal of Software Engineering and Applications, 14, 189-206. https://doi.org/10.4236/jsea.2021.146012

Received: January 28, 2021

Accepted: June 7, 2021

Published: June 10, 2021

Copyright $\odot 2021$ by author(s) and Scientific Research Publishing Inc. This work is licensed under the Creative Commons Attribution International License (CC BY 4.0).

http://creativecommons.org/licenses/by/4.0/

\begin{abstract}
The Building Information Modeling (BIM) methodology considers the representation of the building as a virtual BIM model and its main concept is to centralize all the information generated throughout the development of the project. Structural design involves a set of tasks, namely, structure definition, structural analyses, and after the generation of drawings and technical documentation. In all processes, it is required confidence in data transferred between the BIM systems used, and to support this, a high level of interoperability is claimed. The present study aims to evaluate the degree of interoperability between the BIM-based platforms, ArchiCAD (Graphisoft), Revit (Autodesk), and ETABS (CSI). Two-way data flows between these systems were explored using distinct transfer strategies: add-in applications; Industry Foundation Classes (IFC) standard data format. The research made allows identifying the most appropriate procedure to be adopted by structural engineers, given the interoperability limitations verified, enabling the establishment of a practical guide of sequential procedures on the development of structural designs using BIM tools.
\end{abstract}

\section{Keywords}

Structural Design, BIM Methodology, Interoperability, BIM Tools

\section{Introduction}

The activity associated with the Construction industry is widely supported by technology, which has recently achieved innovative advances aimed at various sectors of the sector. However, the process of developing multi-specialties within a complete project requires the realization of a sequence of phases assigned to 
different technical teams and using distinct tools. The information that is required on the development of each stage, is interpreted essentially from technical drawings, often leading to omissions and data inaccuracies and therefore, to some inconsistency in the final product.

Building Information Modelling (BIM) methodology has been implemented in all domains of the Construction industry around the world. The BIM concept is based on the generation of a single virtual model representative of the building, composed of the distinct specialties involved in a project and of all the information created throughout the building lifecycle [1]. Currently, the BIM concept and the technology associated constitute the main work platform, having provided an incremental collaborative capacity of communication among the design team and supporting an easy information delivery [2]. Within engineer enterprises, the adoption of BIM has led to significant changes in internal organization, in order to admit collaboration centralized in a single BIM model, supporting the different disciplines of a building design [3].

The elaboration of a structural project involves a set of sequential steps, each one requiring specific tools:

- The establishment of a structural solution, that is carried out essentially over the digital drawings of the architectural project;

- The structural analyses, that is performed in a structural calculation system;

- The generation of the technical drawings composed of plants and detailed reinforcements.

In a traditional Computer Aided Design (CAD) mode of work, although some automation is recognized in the process, there is often a considerable volume of repetition, omission, and misinterpretation of data [4]. Within a BIM environment, supported by advanced technology tools available, the structural design can be developed with more effective integration of steps. However, current practice shows that a full, complete, and rigorous data transfer is still problematic. In order to minimize the limitations related essentially to the interoperability capacity, recent researches have been pointing in two directions:

- The establishment of new versions of the international Industry Foundation Classes (IFC) standard more comprehensive and complete;

- The definition of complementary applications like add-in, extensions, and plug-in, enhances the main tool in the elaboration of specific tasks.

\section{Background Research}

The most recent reports concerning the adopting of BIM within structural engineering and design points essentially to collaboration, interoperability, and level of development (LOD):

- The review bibliographic work of Vilutiene et al. [5] demonstrates "that research on BIM applications for structural engineering has been constantly growing with a sudden increase after 2014", but "the number of studies on structural engineering and BIM is still quite low" when compared with other 
areas of BIM application. However, the authors found that the most recent topics concerning structures are related to interoperability, data handling, simulation, automation, cost benefit analyses, and model view definition;

- Following Shin [6] the quality of structures depends on the efficiency of a collaborative work based on a high level of interoperability that can be achieved using an Open BIM platform and the definition of models reaching the LOD 300 requirements;

- Supporting this idea Subramani and Ammai [7] used Primavera, a BIM technology platform, to allow BIM data exchange and the integration of distinct participants from building owners to architects and engineers on the development of structural projects, allowing an adequate communication among the assignment group. Within the Primavera BIM platform, "several activities that included teams engaged in are enhancing, extracting, taking part, updating and placing other applicable facts to the built version database";

- In addition, Musella et al., [8] revel a BIM perspective concerning the managing of structural information after a seismic event occurred in a building, pointing strategies "to mitigate the catastrophic effects of earthquakes on the occupants of a building, as well as improve the management of the emergency that inevitably ensues". In the study, the authors required to openBIM platform based on the standard data format IFC, in order to organize all the information, existed, produced, and changes caused by the seismic action.

As so, both the interoperability ability of the tools available and the type and quantity of information assigned to a BIM model, are the most relevant aspects that have been explored, analyzed, and discussed concerning structural engineering in BIM [9]. The present study intends to contribute in a positive way to a better knowledge of how to use BIM platforms in the structural sector [10].

The BIM methodology is often related only to its most visible aspect, the three-dimensional (3D) geometric representation. However, the BIM virtual model, created along the design process, is composed of parametric objects that, in each case, are selected from the BIM system library and adapted to the real characteristics of the building. The parameters of the objects used on the modeling process are related to the geometry type (wall or column), but also to the physical properties of the materials applied (brick or concrete).

The BIM digital model of a building is first designed with the architectural component and after updated with the information related to other disciplines such as structures and network systems (air conditioning or water supply) [11]. Depending on the project stage, the BIM 3D model may encompass some or all of the specialties. At any phase, it is possible to obtain, by access to the database contained in the created model, different types of drawings, cuts in perspective, or tables of quantities of building components and materials. The consult and management of the model information support the designer in his activity, allowing to be evaluated, in a sustained way, the results of the different alternative 
solutions for the project. In addition, using the model database several tasks, usually designed as $\mathrm{nD}$ dimensions of BIM, can be defined: construction planning (4D BIM) [12]; budgeting (5D BIM) [13]; energy analysis (6D BIM) [14]; management and maintenance (7D BIM). The scope of the applicability of BIM has been recognized, with positive results, by a growing range of professionals in the sector. The advantages of BIM have been reported, not only in relation to the design phase of the different specialties but also on monitoring the construction planning, on estimation cost, or after on the management and maintenance of the building [15].

BIM-based systems present features providing easy access to the model database, leading to adequate communication between the professionals involved, in visual terms and correction of the information transferred, allowing to achieve collaborative projects and, therefore, to obtain an optimized final product. The development of collaborative projects, involving various actors, requires that the systems used, allow a high level of interoperability. The problem of interoperability is an aspect of ongoing research, with the aim of achieving incrementally more efficient stages.

The interoperability concept refers to the ability of one tool to operate with the information created by other systems. The International Alliance for Interoperability (IAI) [16] established, in the $90 \mathrm{~s}$ of the XX century, the first standard data format for the exchange of product model data, allowing designers to transfer file. Later, the IFC standard was created, presenting an internal organization according to a multi-level hierarchy, suitable for facilitating access to the database of the BIM models. The BuildingSMART entity incorporates, in 2005, the AIA association, and currently it is composed of 450 organizations from 18 countries being responsible for developing standards related to data transfer (IFC), processes (Information Delivery Manual, IDM), and terminologies (International Dictionary Framework, IFD).

However, currently the commercial software, with the ability to read the IFC format, still admits only some interpretation of data, as the optimal level of efficiency has not yet been reached. The present study analyses the level of interoperability verified on the use of distinct BIM systems, on the elaboration of the structural design of the building case.

\section{Methodology}

In order to clarify BIM-based tools allows a superior performance supporting the development of the structural project, the present study aims to identify the main potentialities and limitations associated with the process. Two techniques for data transfer were tested, using add-in or the IFC standard, and the main remarks were carried allowing to list an appropriate guide of operation for structural engineers. As a methodology:

- The study analyzes the processes of generation, transposition, and verification of the structural BIM model, throughout different stages of the project 
development;

- The work involves the selection and use of BIM-based tools and the identification and preparation of the information to be used in the modeling and calculation phases;

- After each transfer step, a deep verification concerning the evaluation of the consistency of the data is performed and the required adjustments are made.

As a result, the main advantages found are evidenced by taking care of the existing limitations, allowing to be established an appropriate procedure for action in the structural design sector, which can be followed, in the implementation of the BIM in engineering offices.

\subsection{Case Study Description}

The case study considered is a hotel building located in Algarve, Portugal. The architecture project was provided in a $3 \mathrm{D}$ digital model, created in ArchiCAD system (Graphisoft), a BIM modeling tool widely disseminated in architecture offices (Figure 1). The building is composed of six floors: the basement being intended for pool and gym facilities and technical support areas; the ground floor with the reception, catering and office areas; the three elevated floors allocating the room area; the upper floor, which is indented and allows a panoramic terrace and swimming pool. The building presents an area of $1780 \mathrm{~m}^{2}$ in plant and a longitudinal arrangement segmented into three blocks. In order to allow

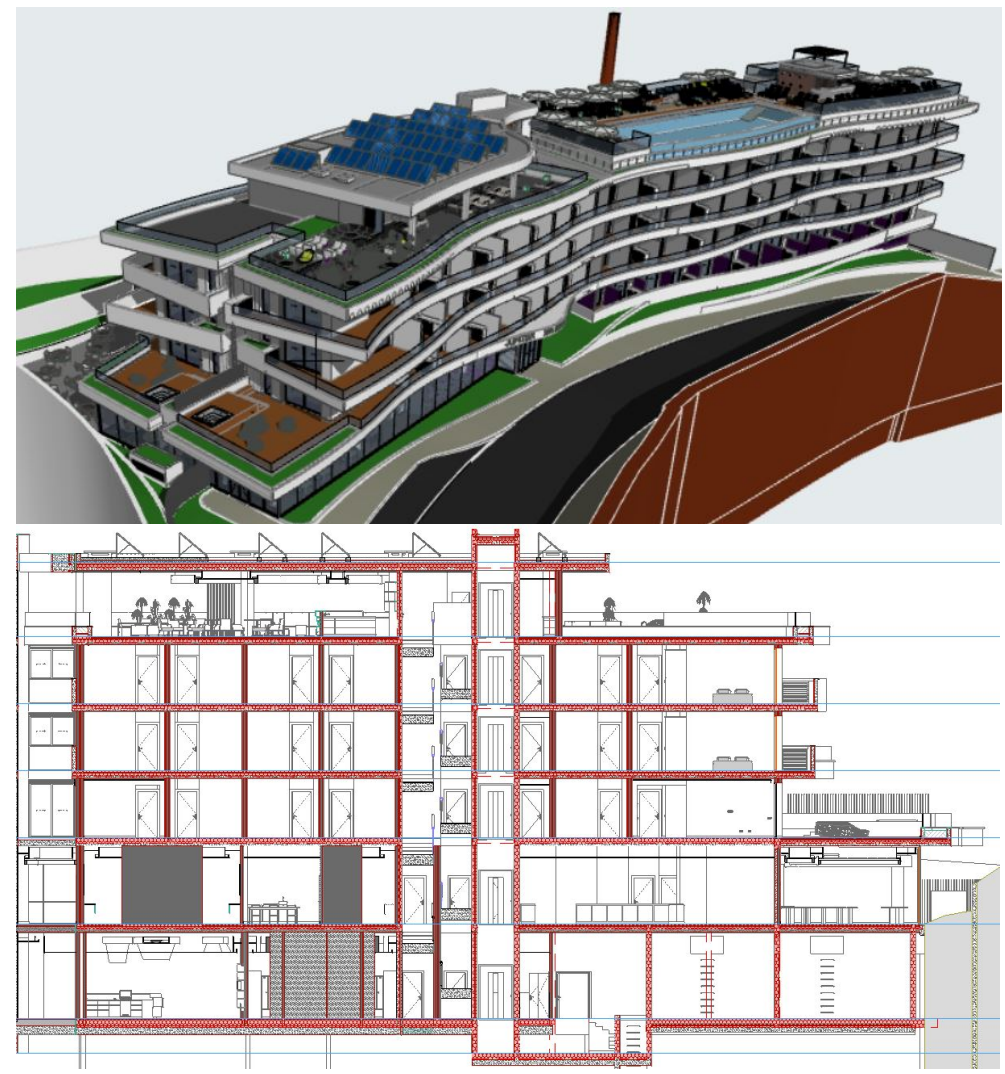

Figure 1. Model of the architectural project of a building hotel. 
the analyses of the suitability of the BIM implementation on structural design, only the southern block of the building was studied.

The structural solution adopted is in reinforced concrete, and considers the constraints imposed by the architecture and type of use:

- The floors are massive fungiform slab, allowing a reduced thickness of $0.25 \mathrm{~m}$ and the easy accommodation of equipment and devices related to the system network (water, sewage, or air conditioning). The solid slab allows to design cantilevers of great extension and with a longitudinal configuration of variable curvature, established in the architectural design;

- The columns admit a rectangular section, and their orientation is predominantly perpendicular to the largest dimension of the building, and their location is coordinated by the metric of the rooms and the future use for floors 0 and -1 ;

- For the underground structural walls were designed, with a height of only $1.30 \mathrm{~m}$ supporting the soil, throughout their perimeter, and interior walls located around the technical areas and elevators were also considered;

- The foundation solution was conditioned by the geological study, previously carried out, and a massive slab of $0.25 \mathrm{~m}$ thickness was adopted, positioned directly over the soil.

\subsection{Structural Model Created in ArchiCAD}

Within the architectural model provided, created in ArchiCAD (Graphisoft) software, some elements of structural characteristic were identified: the floors, represented by composite structures, referring to the link between the concrete slab and the coating; the architectural walls, also represented by the same type of parametric object, as they integrate pillars in their composition. However, in a BIM context, these elements present a very limited parameterization, since they do not allow the assignment of material, the identification of objects as structural characteristics, or the correct dimension of the structural slab that is distinct from the architectural floor.

In order to complete and adjust the model of structures, some additional elements were defined in ArchiCAD. Figure 2 illustrates the characterization of a concrete-structural column of cross/section size $200 \times 835$. Its relative position over the floor, considers the thickness of the coatings, and so, the clean floor does not coincide with the upper architectural level.

Although the ArchiCAD presents obvious limitations of structural modeling, it admits the definition of new materials, through the Building Material option, namely concrete C30/37 and A500NR steel. But it admits just a few parameters, referring only to thermal conductivity, density, or heat capacity, and not to volume mass or coefficients of elasticity and Poisson required later in the structural analyses process. Despite evident limitations, the established structural solution was modeled in order to identify the quantity and type of inaccuracies verified (Figure 3). The structural calculation process requires that the model created 

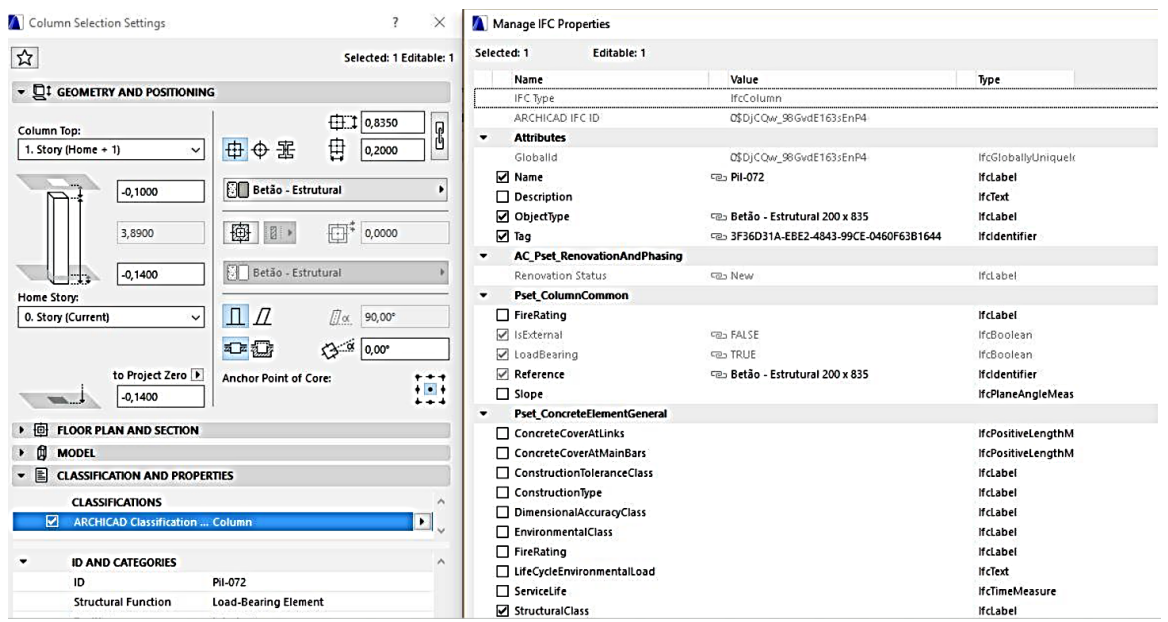

Figure 2. Column generation interface.

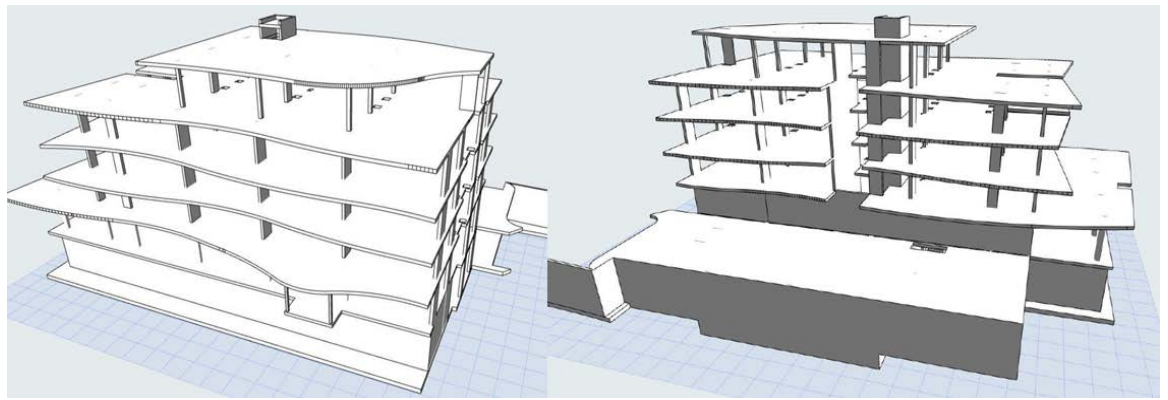

Figure 3. Model of structures in ArchiCAD.

in ArchiCAD should be transferred to Extended 3D (Three-Dimensional) Analysis of Building Systems (ETABS) tool, from Computer and Structures, Inc. (CSI) enterprise, a system widely disseminated in structural engineering offices.

In the present study, the IFC format was used as the data export mode, from the modeling system to the calculation system. Although during the transfer procedure, some ifcObject, like IfcColumns, IfcWalls or IfcSlabs were specifically selected to be transferred, inconsistency errors were detected after transfer. Namely, a large number of adjacent elements become disconnected, requiring a specific check and adjustment. This additional work is time-consuming, but it is necessary to obtain a correct analytical model (Figure 4).

It was found that the transfer process is very limiting. So the strategy of proceed with the structural design was then oriented to the use of a modeling system more compatible with the ETABS application, the Revit (Autodesk).

\subsection{Structural Model Created in Revit}

The structural model defined in ArchiCAD was transferred to Revit, using the ArchiCAD connection an Autodesk Revit extension, made available by Graphisoft. After the model is transferred, 32 warnings were detected, requiring a detailed analysis of the geometry, mainly, the connections between elements. In Revit, all unconnected nodes were fixed. 
The materials, concrete C30/37 and steel A500 NR, were defined in ArchiCAD associated with a reduced set of parameters, and when transposed to Revit only the attributes related to graphic texture of the materials were identified. In addition, a column was found positioned in erroneous orientation and the slab layer of the architectural floor was not identified as a structural component (Figure 5). It was necessary to make some adjustments over the parametric objects with incorrect geometry and physical properties values.

In Revit, the structural elements can be represented according to an analytical view, discretized through linear elements (beams and columns) and surfaces (slabs), by using the Structural Analysis feature. All analytical elements become automatically associated with the correspondent cross-section area and inertias.
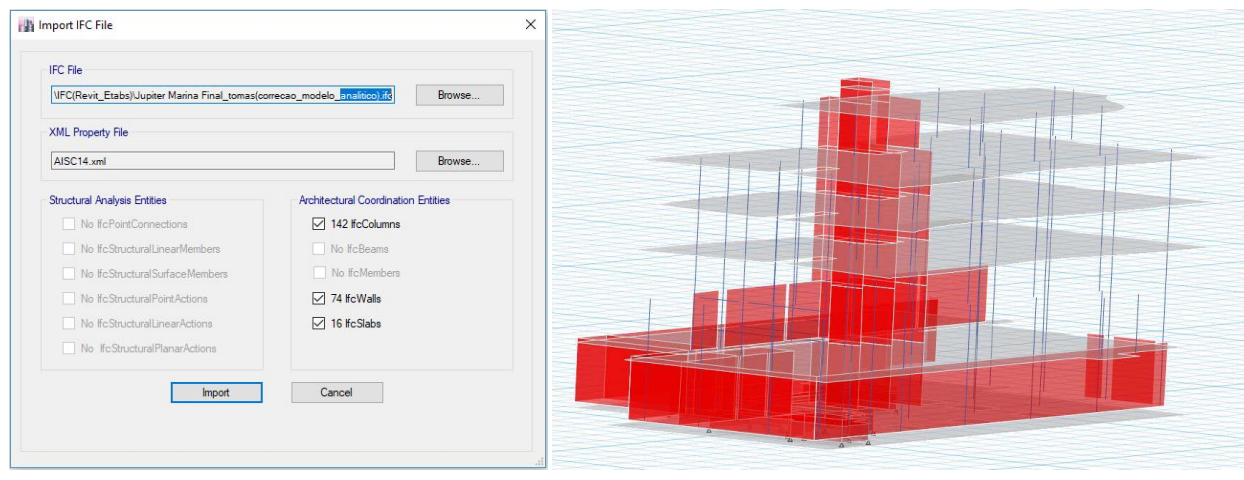

Figure 4. Structural model transposed to ETABS.

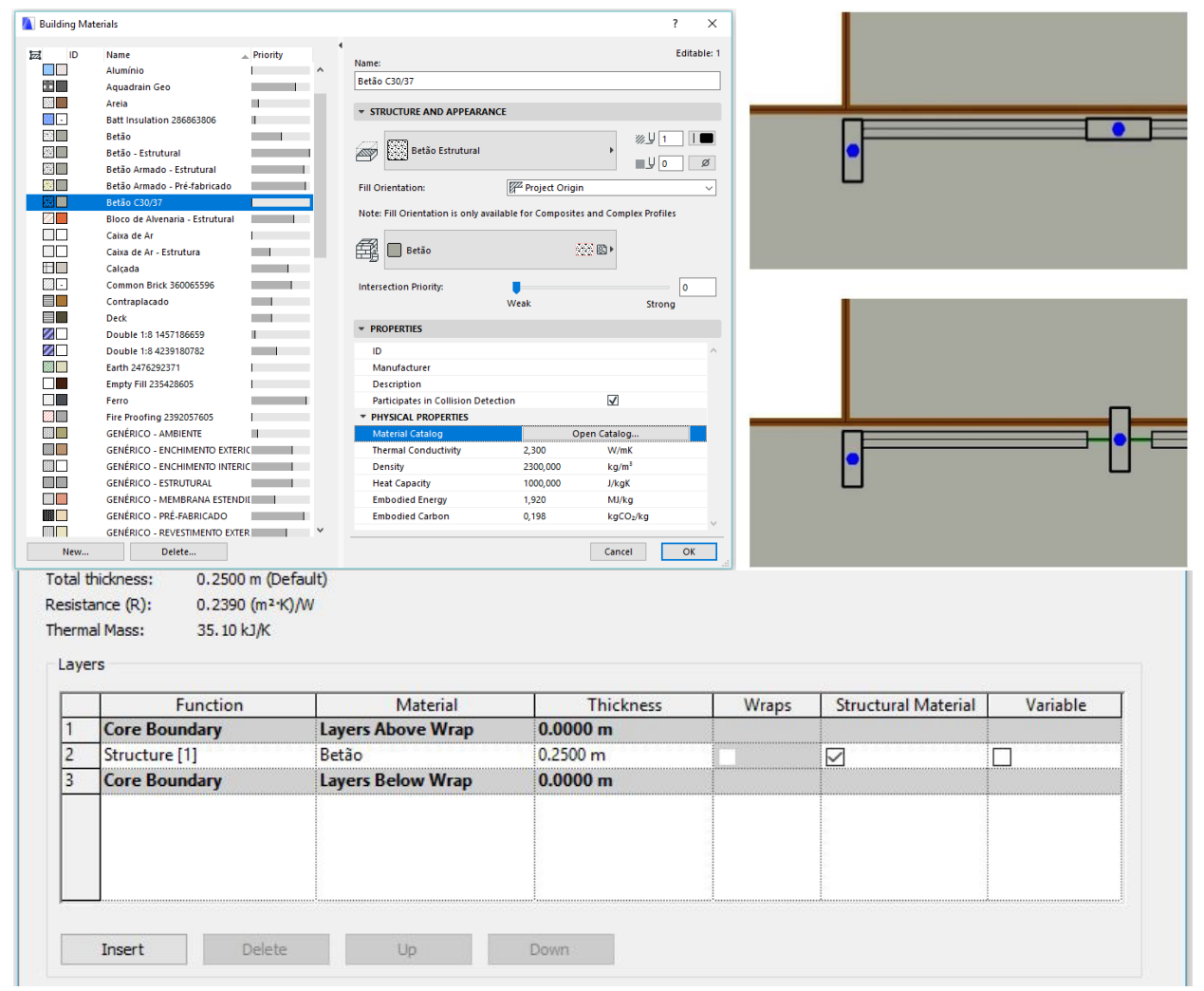

Figure 5. Rectification of the model and properties of the materials, in Revit. 
Prior to the model transfer to the structural analyses system, it was necessary to perform a consistency check (Figure 6):

- The analytical surface of the floor overlaps with the architectural level and not with the average surface of the slab, although identified as a structural element;

- Some of the underground walls and columns present disconnections in relation to the slab middle surface;

- The columns of the higher floors present incorrect location off its analytical axis, in relation to the foundation level.

\subsubsection{Revit Model Transferred to ETABS (CSIXRevit)}

The export process of Revit model to the calculation system can be performed using two procedures: by using the CSIXRevit add-in, available in the modeling tool; or based on the IFC standard. While in the first process, the native format of Revit is recognized directly by ETABS, using the IFC option, the structural model is first archived in Revit as an IFC model, and after it is transferred to ETABS (Figure 7).

In ETABS, a detailed model analyses was again carried out, making it possible to identify some errors and the required corrections were performed (Figure 8):

- The slabs, although modeled with the curvature required in the architecture, lead to a discretization in finite elements as an irregular partition, which led, in a first test, to complex and time-consuming calculations. An alternative feature was applied concerning replacing the curvature of the slab boarder as a set of straight panels simulating an approximate configuration of the existing curved line;

- Again, the connection between the structural wall and the slab element was punctually disconnection, and it was necessary to rectify all incurrences;

- In the foundation slab presents distinct thickness for the purposes of puncture resistance, but after transferred they were identified as voids defined in the slab. The solution of the problem consisted of modeling the slab in contiguous panels, with different thicknesses, in order to represent the zones of simple and reinforced slab.

The refinements carried out over the transferred model contribute to achieve a consistent analytical model, suitable for being used on ETABS system, where the analysis of the structure is executed.

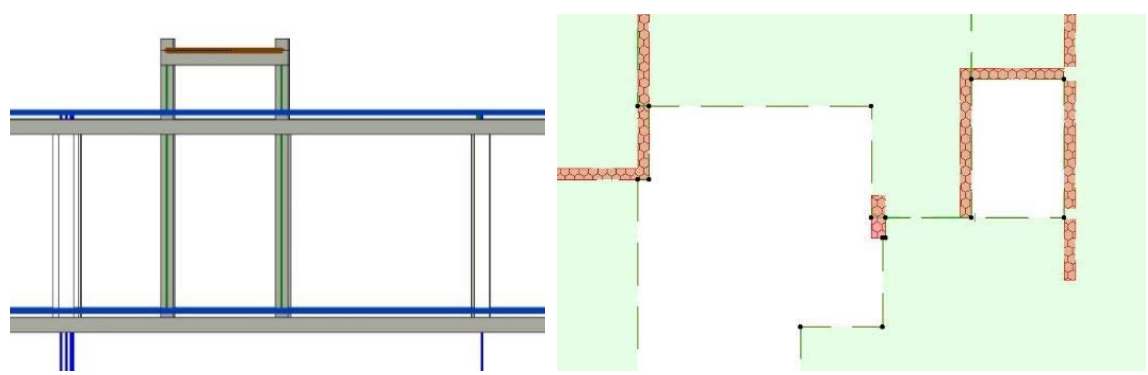

Figure 6. Inconsistencies detect on the structural model tranfered from ArchiCAD to Revit. 


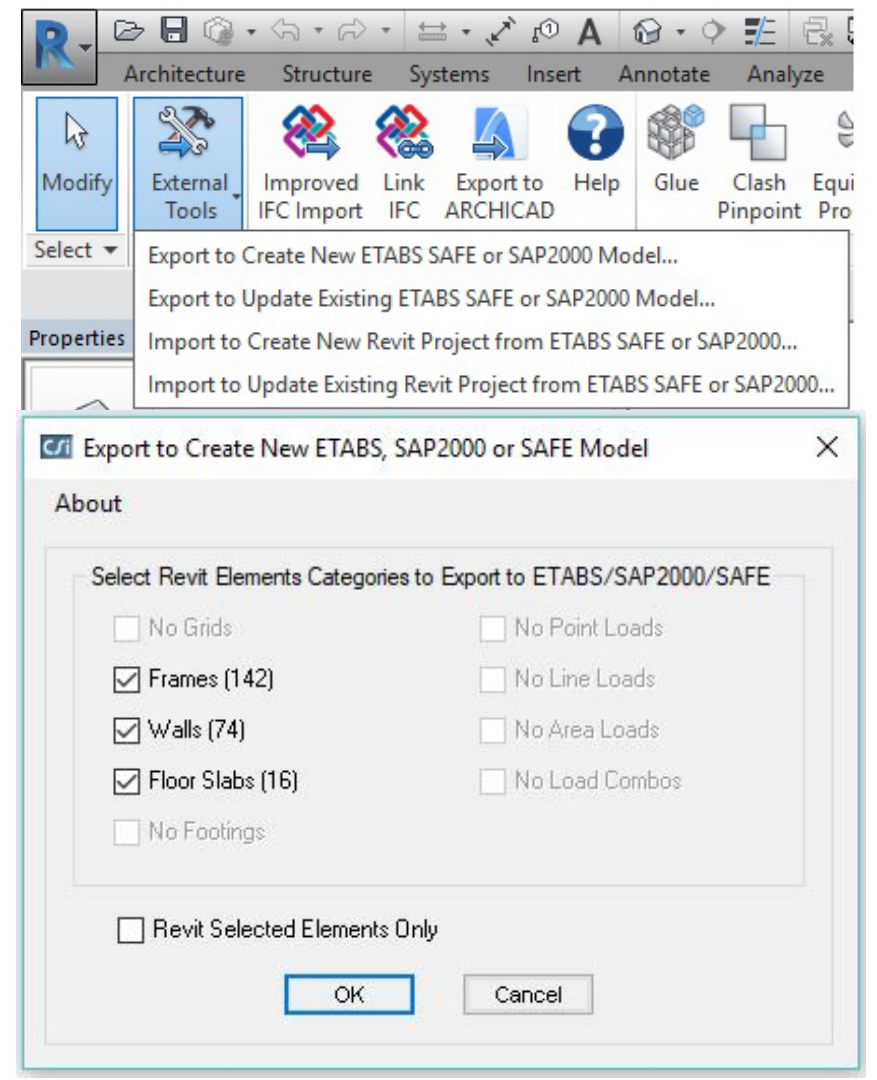

Figure 7. Revit model transfered to ETABS.
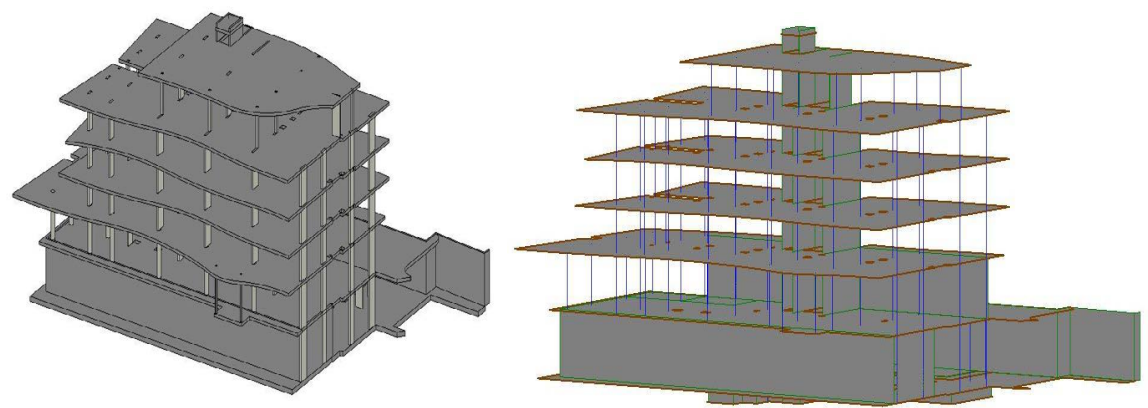

Figure 8. Revit model transfered to ETABS using CSIXRevit add-in.

\subsubsection{Revit Model Transfer to ETABS (IFC)}

The export of the Revit model to the calculation system was also analyzed using the IFC format. In Revit, the analytical structural model is first saved as an IFC model, and after it is transferred to ETABS. In Revit, the IfcObjects to be exported were selected, identified as IfcColumns, IfcWalls, and IfcSlabs, and also obtained the quantity of each type. Then, the model is transferred and a detailed check was made, allowing the identification of a few inaccuracies (Figure 9):

- The slabs, which present curvature in the border edges that were simplified by a set of adjacent panels, are not fully recognized in the analytical model;

- The dimensions of the beams and columns cross-section and the slabs thickens are not associated with the transferred analytical elements; 


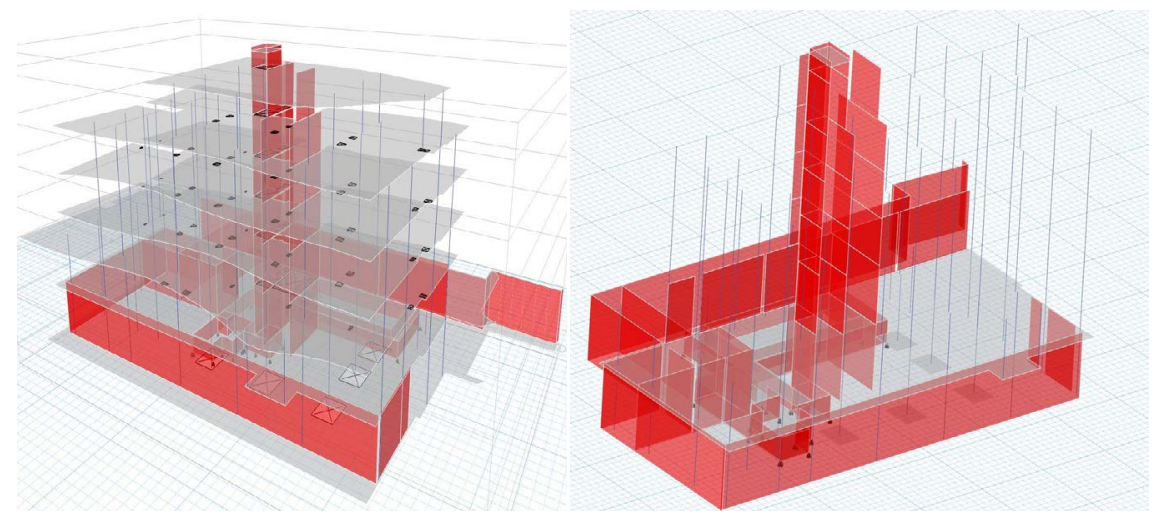

Figure 9. Model structures transposed to ETABS based on CSIXRevit add-in in and IFC standard.

- The physical characteristics associated with the materials of the structural elements are not recognized by the calculation system.

At this point, it is possible to observe that regarding the transfer of the analytical model between Revit and ETABS, the IFC methodology proves to be much less effective than the process in which the CSIXRevit add-in is used. The IFC versions developed and incorporated into the current BIM basic tools, aimed at the structural engineers, are still very limiting. The current trend of the software houses is focused on the development of an increasing number of applications, in the form of extensions or add-in, allowing the increase of the potentialities and functionalities of the main modelling BIM tool, instead of using the IFC format.

\subsection{Structural Analysis}

The main objective of the structural analyses is the definition of a structure that resists the applied loads and combination of loads, so that the structure does not admit collapse (ultimate limit states, ULS) or excessive deformability (service limits states, SLS). In this analyze it was followed the current Portuguese regulations and the Eurocodes available.

According to the standard NP EN 206-1, the type of structural concrete suitable for being applied in an area near the sea is concrete C30/37. Additionally, the A500NR material was selected as a cleaning concrete. The physical proprieties of the materials were associated with the selected parametric objects using the ETABS interfaces (Figure 10).

As ETABS did not retain the geometric characteristics of the analytical model, transferred from Revit, it was necessary to re-establish the pre-dimensioning of the structural elements in this system, using the ETABS interfaces.

\subsubsection{Dimensioning}

The determination of the efforts in the structure was carried out from a 3D analytical model with six degrees of freedom per node (Figure 11):

- In shell finite elements, representing the slabs of the floors, rigid diaphragms positioned in the middle plane of the slab were considered; 


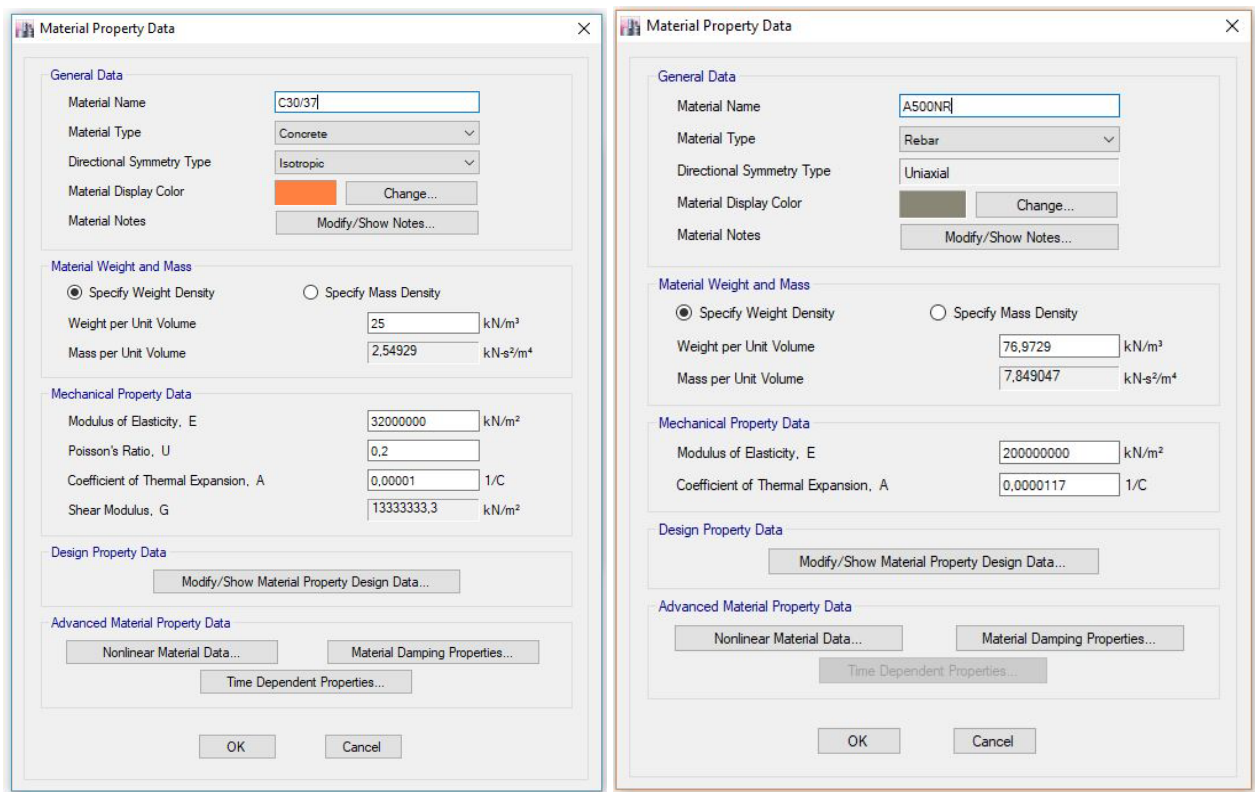

Figure 10. Physical properties of materials defined in ETABS.
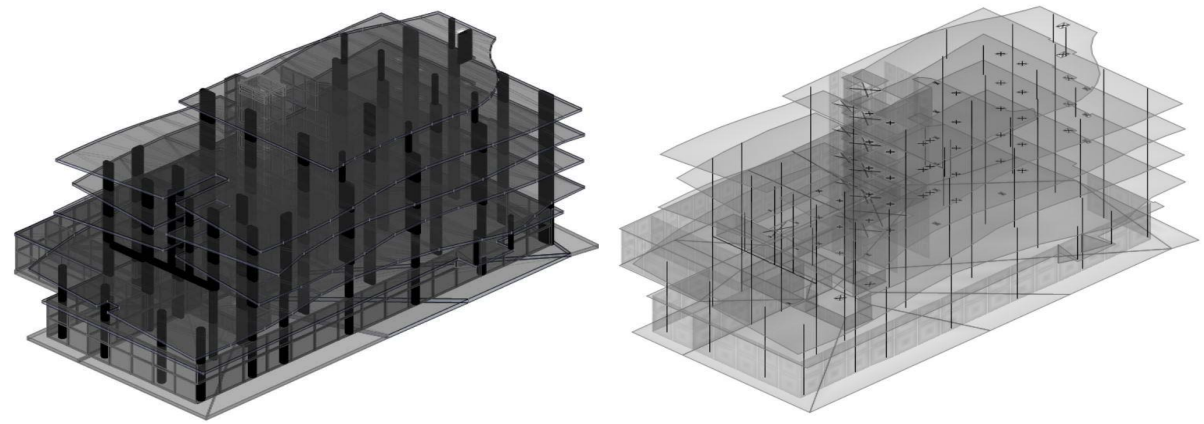

Figure 11. Analitycal model in ETABS.

- Around the shell elements representing the slab foundation, elastic supports were materialized by springs with stiffness defined according to the characteristics of the soil;

- Each structural element was associated with appropriate mechanical characteristics resulting from its geometry and the properties of the materials used.

The next step is to apply the loads and required combinations of loads over the analytical model, performed in ETABS:

- The permanent load relating to the structural own weight (PP) are automatically assumed by system, using the volume weight of the reinforced concrete, with a value of $25 \mathrm{kN} / \mathrm{m}^{3}$;

- The permanent load (PC) relating to the distinct coating applied on different zones of the building;

- The variable load (SC) considers the type of use that is distinct on each floor or zone;

- The soil impulse is considered $9 \mathrm{kN} / \mathrm{m}^{2}$, determined according to the coefficient $\mathrm{Ks}=0.5$ and the weight of the soil of $18 \mathrm{kN} / \mathrm{m}^{3}$; 
- In relation to the seismic action, as the building is located in the seismic Portuguese zone A, the correspondent coefficient considered is $\alpha=1$, and the type of land admitted is of type II.

To perform the dynamic analysis, the seismic action was quantified by means of the response spectra for a damping coefficient of 0.05 , considering a seismic action of moderate to small focal magnitude (SISM1-Left) and a seismic action of greater magnitude at a higher focal length (SISM2-Right). The masses considered were concentrated, at the level of each floor, positioned in the center of the floors and considering the respective inertia moments. The seismic action was applied according to the two orthogonal directions, longitudinal and transversal of the building, and the first modes of vibration were calculated. The response of the structure to it was determined by the Complete Quadratic Combination (CQC) method and also by the Square Root of the Sum of Squares (SRSS) method. In order to obtain the value of the efforts due to the seismic action, and considering a linear behavior of the structure, a coefficient value of 2.5 was admitted, considering a normal ductility effect:

- For the determination of the deformed structure, two combinations of actions were considered: $1 \mathrm{PP}+1 \mathrm{CP}$ and $1 \mathrm{PP}+1 \mathrm{CP}+0.4 \mathrm{SC}$;

- For the determination of the maximum sizing efforts in the structure, the following combinations were considered: $1.35 \mathrm{PP}+1.35 \mathrm{CP}+1.5 \mathrm{SC}, 1 \mathrm{PP}+$ $1 \mathrm{CP}+0.4 \mathrm{SC}+1.5 \mathrm{SISM} 1$ and $1 \mathrm{PP}+1 \mathrm{CP}+0.4 \mathrm{SC}+1.5 \mathrm{SISM} 2$;

- For the dimensioning of the foundation elements, the soil characteristics consulted from the geological study available, a limestone massif with a maximum load absorption capacity of $200 \mathrm{KPa}$, was considered.

\subsubsection{Reinforcements Detailing}

ETABS enables the determination and graphical presentation of stresses and deformations and calculates the required reinforcement areas by element. In relation to the slabs of the floors, a base reinforcement composed of a square mesh consisting of $12 \mathrm{~mm}$ rods away from $0.2 \mathrm{~m}$ was adopted, arranged on both sides of the slab, and depending on the moments obtained, for the heaviest actions, the additional reinforcements required were established (Figure 12).

ETABS determines also the area of reinforcement necessary for all beams and columns. It was found that the geometry of a column was insufficient, requiring to increase its cross-section, so that the required reinforcement percentage did not exceed a value of $4 \%$ of the cross-section area. ETABS presents interfaces allowing the defining of the reinforcements detailing in all structural components (Figure 13).

\subsection{Centralization of Information}

According to the basic concept of the BIM methodology, the development of different disciplines concerning a building project should be elaborated on a single centralizing model and all the information generated should comprise a unique database. The information created in the structural analyses task should 
be transferred to the initial model, completing the model with this step. For that, the results of the structural analyses performed in ETABS are now transferred to the BIM model created in ArchiCAD and refurbished in Revit (Figure 14). The transfer process is made in an inverse way of the one defined previously ArchiCAD/Revit/ETABS. Now the way flow of information is made in the direction $\mathrm{ETABS} /$ Revit/ArchiCAD, allowing to evaluate the level of interoperability of the
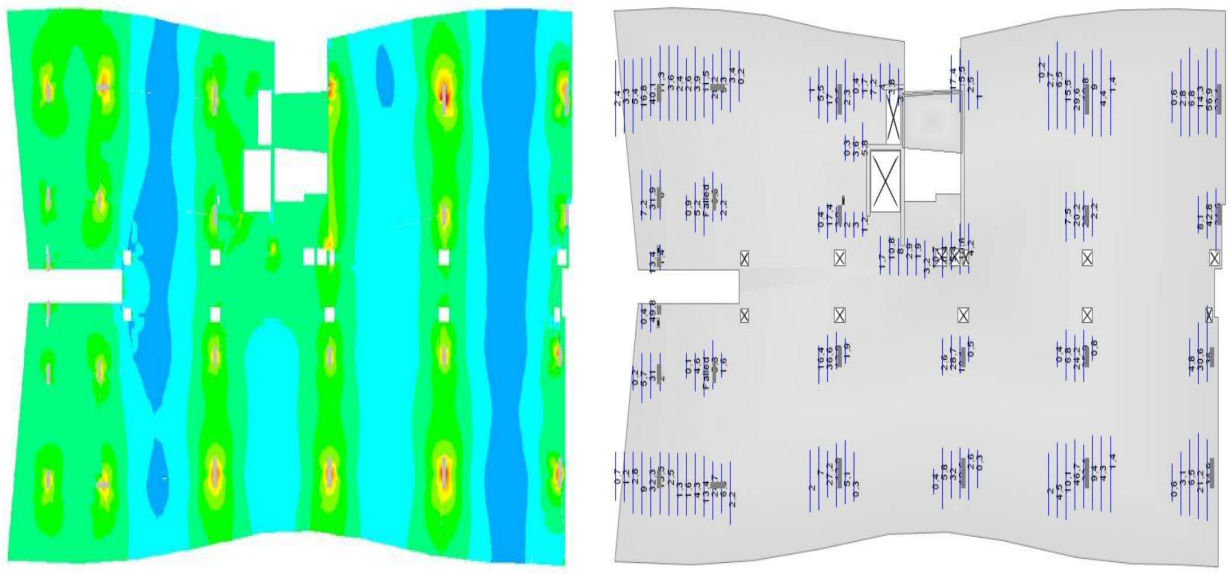

Figure 12. Moments on the slab and reinforcments in the upper surface.

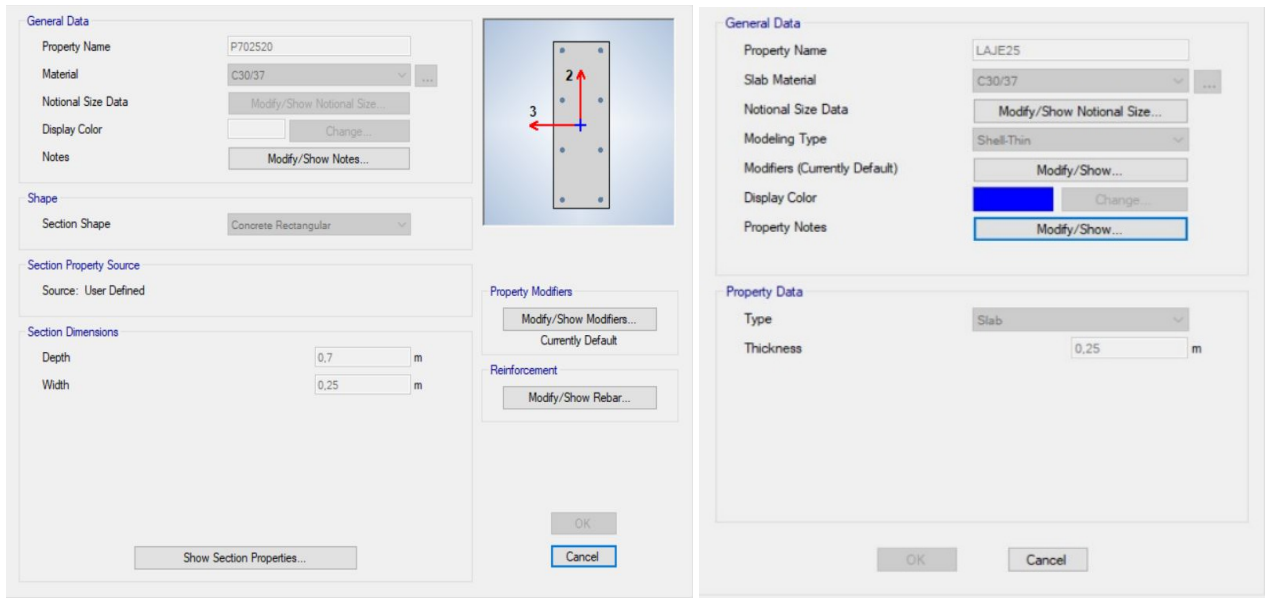

Figure 13. ETABS interfaces for the reinforcements detailing on beams and slabs.
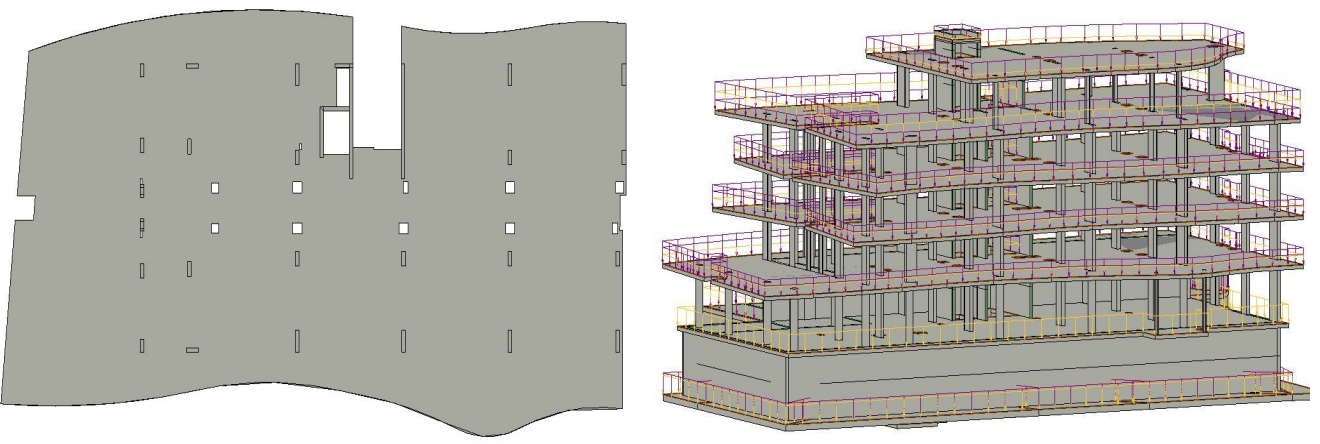

Figure 14. Updated slab and model in Revit with the ETABS information. 
systems, in the two-way flows of data.

Although ETABS has a higher capacity of production technical drawings, the information of the reinforcements detailing are not eligible to be exported in IFC format and ETABS does not present extensions to support the transfer of IFC models. Then, the reinforcements data should be performed later only in Revit, or even in ArchiCAD. However, in the present study the result of the structural analyses, namely, diagrams of stresses and deformations and areas of required reinforcements, were admitted to be transferred from ETABS first to Revit and after to ArchiCAD.

\subsubsection{Transfer from ETABS to Revit}

The transfer process from ETABS to Revit is supported in the export feature available, the add-in Revit Structure.exr File. In Revit, the initial model is now updated with the imported data and a detailed check is required in order to re-define the elements that were added, omitted, and changed in relation to the initial model.

Revit allows an overlapping view formed by the transposed and the initial models. It allows the engineer to analyze the structural solution in both stages before and after dimensioning. In this process Revit automatically detects the inconsistencies and errors originated, having been verified some incoherencies related to elements presenting slightly in relation to their axis or inaccuracies in nodes that are not joined. A thorough assessment of each error has been carried out and accordingly, the necessary adjustments and corrections have been made.

Once the check is complete, it is possible to conclude that the structural model in Revit did not admit significant changes, having, for the most part, warnings and errors, the origin of simplifications made in the analytical model in ETABS, to facilitate dimensioning and accommodate the changes required in geometry of some elements. On the updated Revit model, the reinforcement detailing should be carried out. According to recent reports [17] [18], this BIM task is still conducted under an evident limitation of interoperability.

\subsubsection{Transfer from Revit to ArchiCAD}

Once the Revit model upgrade process is complete, it is then transposed to the ArchiCAD system. The process is executed using the export functionality available in REVIT. After this process is finished, ArchiCAD is allowed to compare the initial and the imported models using the Option Mark Up Tool, and different colors are assigned to the elements, enabling the visual identification of the deleted, generated and modified elements. All changes were analyzed concerning geometry and the parametric objects contained (Figure 15). In it, several adjustments were made in order to support the analysis results.

\section{Results and Discussion}

The study analyzed the processes involving two-way data flows of information between the BIM systems required for the development of the structural design. 


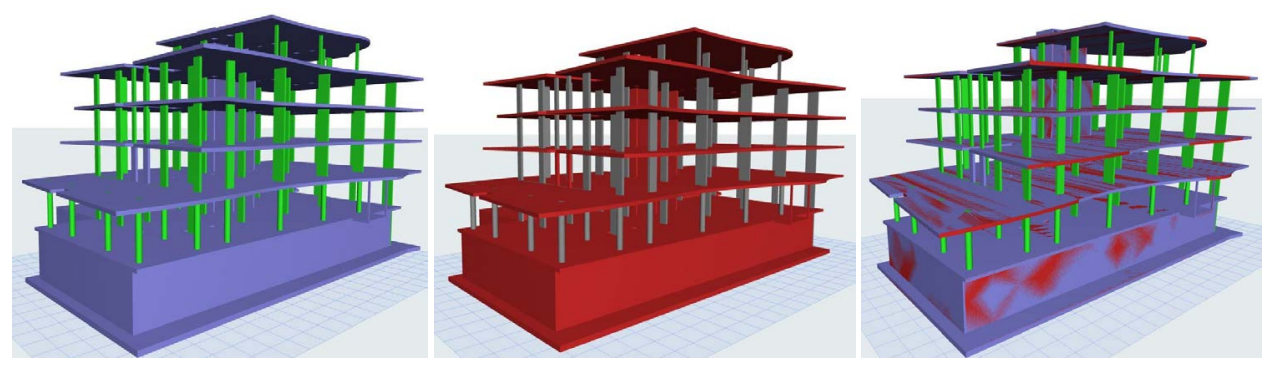

Figure 15. Structural model represented in its initial, updated and overlaped stages.

The main perspective was to evaluate the degree of interoperability capacity verified in several steps throughout all processes, namely, structural generation, structural analyses and reinforcements detailing.

The selected case study is a building for hotel use. The complex architectural configuration presented requires a specific structural solution suitable to accomplish all the architectural constrains. As the architectural project was developed in the ArchiCAD (Graphisoft), a BIM-based system, the structural model was also initially created in the same tool, using the architectural references. However, some adjustments at the floor levels were required as well as correction on structural elements connections and on the association of materials to the parametric objects used. The model is then transferred to the structural analyses tool, the ETABS (CSI), and a few consistency errors were detected and adjusted, denoting that the interoperability capability verified is inefficiency. It was therefore necessary to provide the use of an intermediate platform, the Revit (Autodesk).

The interoperability assessment was analyzed at different stages of information transfer: between ArchiCAD and Revit, according to distinct procedures, using add-in and IFC format; between Revit and ETABS; and, later, in the inverse way, between ETABS, Revit and ArchiCAD. After each transfer, a deep analysis was made over each transferred model, in relation to the consistency of the analytical geometry and the physical properties, preserved, omitted, or changed. After the structural analysis is performed in ETABS, the model of structures is transposed to Revit and after to ArchiCAD in order to obtain a single BIM model, updated and correct, with the information created in the structural design phase.

\section{Conclusions}

The main conclusion of the study can be formalized in a practical guide when the architecture design is provided in ArchiCAD and the structural analyses, is developed using ETABS:

- Create an initial structure model in ArchiCAD, representative of the structural solution defined in accordance with the architectural conditions;

- Transfer the model to Revit, using the add-in for Autodesk Revit extension available in ArchiCAD, and not the IFC format;

- The consistency of the analytical model must be verified and correct values of the materials proprieties must be associated with the parametric objects; 
- Transfer the Revit model to ETABS and a new re-evaluation of its consistency and properties must be made;

- The structural analyses must be realized in ETABS and, in accordance with the results, the reinforcements details drawings must be obtained;

- Finally, the final structural model must be transferred to Revit, using the add-in mode, and after to ArchiCAD.

This text summarizes the main aspects related to the interoperability analysis related to the three BIM base systems, most frequently used, in structural projects, being presented the limitations found, referred to the solution strategies, and identified the benefits. The advantages are essentially related to the easy initial modeling and with some ability to transfer information post-calculation between software. Finally, it is noted that the biggest limitation concerns the inefficient interoperability that still exists, concerning structural engineering.

\section{Conflicts of Interest}

The authors declare no conflicts of interest regarding the publication of this paper.

\section{References}

[1] Sacks, R. and Barak, R. (2010) Teaching Building Information Modeling as an Integral Part of Freshman Year Civil Engineering Education. Journal of Professional Issues in Engineering Education and Practice, 136, 30-38.

https://doi.org/10.1061/(ASCE)EI.1943-5541.0000003

[2] Succar, B. (2009) Building Information Modelling Framework: A Research and Delivery Foundation for Industry Stakeholders. Automation in Construction, 18, 357 375. https://doi.org/10.1016/j.autcon.2008.10.003

[3] Azhar, S. (2010) Building Information Modeling (BIM): Trends Benefits, Risks and Challenges for the AEC Industry. ASCE Journal of Leadership and Management in Engineering, 11, 241-252. https://doi.org/10.1061/(ASCE)LM.1943-5630.0000127 https://ascelibrary.org/doi/pdf/10.1061/ \%28ASCE\%29LM.1943-5630.0000127

[4] Sampaio, A.Z. (2017) BIM as a Computer-Aided Design Methodology in Civil Engineering. Journal of Software Engineering and Applications, 10, 194-210. https://doi.org/10.4236/jsea.2017.102012

[5] Vilutiene, T., Kalibatiene, D., Hosseini, M.R., Pellicer, E. and Zavadskas, E.K. (2019) Building Information Modelling (BIM) for Structural Engineering: A Bibliometric Analysis of the Literature. Advanced Civil Engineering, 2019, Article ID: 5290690. https://doi.org/10.1155/2019/5290690

[6] Shin, T.S. (2017) Building Information Modeling (BIM) Collaboration from the Structural Engineering Perspective. International Journal of Steel Structures, 17, 205-214. https://doi.org/10.1007/s13296-016-0190-9

[7] Subramani, T. and Ammai, A. (2018) Maturing Construction Management Up the BIM Model and Scheduling Using Primavera. International Journal of Engineering \& Technology, 7, Article ID: 15617. https://doi.org/10.14419/ijet.v7i3.10.15617

[8] Musella, C., Serra, M., Salzano, A., Menna, C. and Asprone, D. (2020) Open BIM Standards: A Review of the Processes for Managing Existing Structures in the Preand Post-Earthquake Phases. Civil Engineering, 1, 291-309.

https://doi.org/10.3390/civileng1030019 
[9] Araszkiewicz, K. (2017) Digital Technologies in Facility Management-The State of Practice and Research Challenges. Procedia Engineering, 196, 1034-1042.

https://doi.org/10.1016/j.proeng.2017.08.059

[10] Farinha, T.T. (2018) Analysis of the Process of Transposition of Information between Structural Models in BIM Environment. MSc Thesis, University of Lisbon, Portugal.

[11] Sacks, R., Eastman, C., Lee, G. and Teicholz, P. (2018) BIM Handbook, a Guide to Building Information Modeling for Owners, Managers, Designers, Engineers, and Contractors, 3rd Edition, John Wiley \& Sons Inc., New Jersey, Hoboken. https://doi.org/10.1002/9781119287568

[12] Sampaio, A.Z. and Mota, C. (2016) BIM Model of Structures Used in Construction Planning, Proceedings of the National Meeting of Structural Concrete. BE2016, Coimbra, Portugal, 2-4 November 2016, 44-53.

[13] Antunes, B.M. (2018) Measurement of Work Quantities in Traditional Environments and BIM: Comparative Analysis of Concrete and Formwork Measurements in Structures Projects, MSc Thesis, University of Lisbon, Portugal.

[14] Sampaio, A.Z., Araújo, L. and Coelho, E. (2019) Building Information Modelling capability in an Energetic Simulation Perspective. Proceedings of the 2 nd International Congress on Engineering and Sustainability in the XXI Century, Faro, Portugal, 9-11 October 2019, 465-477. https://doi.org/10.1007/978-3-030-30938-1_37

[15] Sampaio A.Z. and Lozano-Diez, R. (2020) BIM Short Course Oriented to Professionals of the Construction Industry, ABE-Advances in Building Education. Innovación Educativa en Edificación, 4, 23-34. https://doi.org/10.20868/abe.2020.3.4508 http://polired.upm.es/index.php/abe/article/view/4508

[16] BuildingSMART. https://www.buildingsmart.org/

[17] Borges, N.R. (2019) Structure Design Supported by BIM Methodology: Structural Analysis and Detailing of Reinforcements. MSc Thesis, University of Lisbon, Portugal.

[18] Rodrigues, I.G. (2019) Development of the Project of Structures Using BIM Tools. MSc Thesis, University of Lisbon, Portugal. 